Discussion Paper No. 07-001

Do Hiring Subsidies Reduce Unemployment Among the Elderly?

Evidence From

Two Natural Experiments

Bernhard Boockmann, Thomas Zwick, Andreas Ammermüller, and Michael Maier

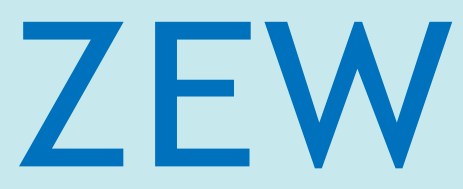

Zentrum für Europäische Wirtschaftsforschung $\mathrm{GmbH}$

Centre for European

Economic Research 


\title{
Discussion Paper No. 07-001 \\ Do Hiring Subsidies Reduce Unemployment Among the Elderly? Evidence From Two Natural Experiments
}

\author{
Bernhard Boockmann, Thomas Zwick, \\ Andreas Ammermüller, and Michael Maier
}

Download this ZEW Discussion Paper from our ftp server:

ftp://ftp.zew.de/pub/zew-docs/dp/dp07001.pdf

Die Discussion Papers dienen einer möglichst schnellen Verbreitung von neueren Forschungsarbeiten des ZEW. Die Beiträge liegen in alleiniger Verantwortung der Autoren und stellen nicht notwendigerweise die Meinung des ZEW dar.

Discussion Papers are intended to make results of ZEW research promptly available to other economists in order to encourage discussion and suggestions for revisions. The authors are solely responsible for the contents which do not necessarily represent the opinion of the ZEW. 


\section{Nontechnical Summary}

Older workers frequently have difficulties to find new work after unemployment. In 1998, the German government introduced the Integration Supplement for Older Workers (Eingliederungszuschuss für ältere Arbeitnehmer, EGZ), hiring subsidies targeted at workers aged 50 and above. Compared to hiring subsidies in other countries, the Integration Supplement is a generous program. According to the rules applying during the observation period, up to 50 per cent of standardized labor costs could be paid over an interval of 24 months.

This study is part of the evaluation of the "Hartz laws" commissioned by the German Federal Ministry of Labor and Economic Affairs. We examine whether eligibility to the program increases the chances to make the transition from unemployment to employment. The effect of eligibility on the transition rate into employment has been studied less frequently than the effect of actual subsidy receipt on integration into unsubsidized employment. However, the former effect is a precondition for the latter: if the availability of subsidies does not change hiring behavior, there is no reason why subsidies should affect individual transitions into unsubsidized employment.

To estimate the effect of eligibility, we use two changes in the legal rules. Our first set of estimates is based on an extension of the group of eligible unemployed persons introduced in 2002. Our second set of estimates validates these results by evaluating the unification of the Integration Supplement for Older Workers and the general Integration Supplement in 2004, which made workers aged above and below 50 years of age equally eligible to subsidy receipt. In both cases, we compare the transition rate from unemployment to employment of a group of workers affected by the change (workers aged 50) with a similar but unaffected group (workers aged 49) during the first 180 days of unemployment.

Data from the Integrated Employment Biographies (IEB), an administrative data set collected and provided by the German Federal Employment Agency, are used. The data cover all unemployed individuals, which is important to forming treatment and control groups of appropriate sizes. 
Estimates from duration analysis of the transition rate show that, for the population as a whole, the probability of leaving unemployment and entering employment is unaffected by the availability of hiring subsidies. For women in East Germany, however, extending eligibility led to an increase in exit from unemployment by six percentage points, while the ending of the specific subsidy program for older workers lowered their employment chances by about two percentage points. Further analysis shows that the ineffectiveness for most population groups is due to deadweight effects: an increase in subsidized hirings is accompanied by a decline in unsubsidized new employment. 


\title{
Do Hiring Subsidies Reduce Unemployment Among the Elderly? Evidence From Two Natural Experiments
}

\author{
Bernhard Boockmann* \\ Thomas Zwick \\ Andreas Ammermüller \\ Michael Maier
}

Centre for European Economic Research (ZEW)

P.O. Box 103443

D-68034 Mannheim

\begin{abstract}
We estimate the effects of hiring subsidies for older workers on transitions from unemployment to employment in Germany. Using a natural experiment, our first set of estimates is based on a legal change extending the group of eligible unemployed persons. A subsequent legal change in the opposite direction is used to validate these results. Our data cover the population of unemployed jobseekers in Germany and was specifically made available for our purposes from administrative data. Consistent support for an employment effect of hiring subsidies can only be found for women in East Germany. Concerning other population groups, firms' hiring behavior is hardly influenced by the program and hiring subsidies mainly lead to deadweight effects.
\end{abstract}

JEL-Codes: J 64, H 24, C 31

Key Words: Hiring subsidies, older workers, evaluation, natural experiments

Acknowledgements: This study was conducted as part of the evaluation of the proposals of the Hartz Commission. We wish to thank the former Federal Ministry of the Economy and Labor (BMWA) for financial support. All results and opinions are our own and do not represent those of the BMWA or its successors. We wish to thank Bernd Fitzenberger, Christian Göbel, Reinhard Hujer, Michael Lechner, and Conny Wunsch for helpful comments and Christoph Junkert for competent research assistance.

*Corresponding author. Tel.: +49-621-1235-156, Fax: +49-621-1235-225, E-mail: boockmann@zew.de. 


\section{Introduction}

Among active labor market policies for disadvantaged labor market groups, hiring subsidies ${ }^{1}$ play an important role in most OECD countries (Martin and Grubb, 2001). Examples are programs within the New Deal for Young People (NDYP) in the UK (Blundell et al., 2004; van Reenen, 2004), the Targeted Jobs Tax Credit, Work Opportunity or Welfare to Work Tax Credit programs in the USA (Katz, 1998; Hamersma, 2005), or the Special Youth Employment and Training Program in Australia (Knight, 2002). The object of hiring subsidies is to increase demand for workers from the target group, thereby raising their employment rates and earnings. Theoretically, the employment effects of these subsidies are well understood (Katz, 1998). The empirical evidence, however, differs between programs, countries and time periods and is frequently plagued by data and estimation problems.

This paper presents estimation results for the effect of the Integration Supplement, a hiring subsidy in Germany, on subsequent exit from unemployment. We concentrate on older employees as a disadvantaged group on the labor market. These workers are often perceived by companies as less productive and less flexible and yet more costly to employ than younger workers. As a consequence, unemployment rates, unemployment durations and wage losses after unemployment are relatively high among older workers.

Our study extends the empirical evidence in several ways. First, we use a natural experiment to identify the effect of eligibility for subsidies on the duration of unemployment. For credible identification, we use treatment and control groups that differ only to a very small degree with respect to age and are identical with respect to other observable characteristics. The effect of eligibility on the transition rate into employment has been studied less frequently than the effect of actual subsidy receipt on integration into unsubsidized employment. However, the former effect is a precondition for the latter: if the availability of subsidies does not change hiring behavior, there is no reason why subsidies should affect individual transitions into unsubsidized employment. Second, by using two changes that first relaxed and later tightened criteria for eligibility, we can

1 Hiring subsidies should be distinguished from wage subsidies. According to Orszag and Snower (2003), hiring subsidies are targeted at the unemployed and provided only for a limited period of time while wage subsidies are paid to employers for an indefinite period and are meant to promote employment for all workers below a certain wage level. 
validate the estimated effects of each change and assess the credibility of identification. Third, we derive a measure of deadweight effects by comparing the estimated employment effect to the number of subsidies disbursed. Our study is based on official register data from the German Federal Employment Agency. This data contains detailed information at the individual level. It is otherwise unavailable for evaluation purposes and has been drawn specifically for our study. ${ }^{2}$ The data cover all unemployed individuals, which is important to forming treatment and control groups of appropriate sizes.

In the next section, we state our main research question and review the empirical literature. We then describe the Integration Supplement for Older Workers in detail and place it into the context of German active labor market policies. Next, we introduce the data. Section five outlines our estimation approach. Empirical results are presented in section six. We provide some robustness checks in the seventh section, while a summary of the implications from our findings is contained in the final section.

\section{Research question and previous empirical evidence}

Hiring subsidies raise two different policy questions that should be distinguished (Martin, 2000; Marx, 2001):

(1) Does program participation lead to a higher probability of being in unsubsidized employment in the future as compared to non-participation?

(2) Do hiring subsidies lead to more hirings and, hence, to earlier transitions from unemployment to (subsidized or unsubsidized) employment among eligible persons, as compared to the situation in which no subsidies are available?

The first question is asked in most evaluation studies on active labor market policies in general, and hiring subsidies in particular. In this paper, we are exclusively concerned with the second question which has been analyzed less often in the literature. It can be seen as a precondition for evaluating the effects of subsidized hiring on regular employment because it concerns hiring behavior of firms as a reaction to the availability of the subsidies. If hiring behavior is

2 Access to the data has been granted to several research institutes evaluating the effects of the socalled "Hartz reforms" under commission by the German Federal Ministry of Labor and Economic Affairs. The data and files used for statistical analysis are stored at the Institute for Employment Research (IAB) of the Federal Employment Agency. 
unaffected by the subsidy, there is no meaningful treatment at the individual level, the effects of which could be estimated. In our case, treatment is defined as the eligibility for program participation, not actual program participation, and the outcome is the time it takes to exit from unemployment to employment. A natural experiment design is used to estimate treatment effects, based on two changes to eligibility described in detail in the third section.

There are different reasons why subsidies may fail to induce additional hirings and shorten unemployment durations. 3 Hiring subsidies lower net wages paid by the employer for the time the benefits are paid. The strength of the employment effect depends on the wage elasticities of labor demand and supply (Katz, 1998; Bell et al., 1999). If either is inelastic, the subsidy will not enhance employment of workers eligible to the subsidy. The only effect is that employers or employees benefit financially, depending on which side reacts inelastically. This outcome has been termed a deadweight effect (de Koning, 1993; Meyer, 1995). A deadweight effect occurs if employers collect the subsidy but hire the same individuals they would have hired had the subsidy not been available. Assessing the magnitude of deadweight effects is a main objective of our empirical analysis.

Even if subsidies are effective for employment of eligible workers, they may be ineffective for total employment. Improvements in employment chances of eligible persons could be countered by a worsening of prospects among other groups (Bell et al., 1999; Blundell et al., 2004; Martin, 2000; OECD, 1990). Crowding-out could take the form of substitution if unsubsidized workers are laid off while subsidized workers with otherwise similar characteristics are hired. Moreover, displacement effects may occur if, for instance, firms using subsidized employment take the place of competitors not using subsidized employment.

With singular exceptions such as the unemployment insurance bonus experiments analyzed by Meyer (1995), existing studies universally rely on nonexperimental variation. Regarding the effects on unsubsidized employment (the first policy question stated above), statistical matching is frequently applied. A control group of unsubsidized workers or persons out of work is generated to construct the counterfactual of non-treatment for individuals for whom hirings subsidies are paid (Lorenz, 1988; Hollenbeck and Willke, 1991; Jaenichen, 2002;

3 Reasons not discussed here are that financial incentives are too low, administrative costs are too high, or companies are unaware of the subsidy program (Marx, 2001). The presence of these reasons can best be detected in implementation studies (see section 4 below). 
Knight, 2002; Sianesi, 2003; Forslund et al., 2004; Hamersma, 2005; Cockx and Göbel, 2005). There are a number of problems with this approach: the likely presence of unobservable differences between treatment and control group, selectivity in the decision who is subsidized, and changes in the composition of the groups over time (Katz, 1998). 4

Among existing studies for exit from unemployment (the second policy question), some are based on opinion surveys among employers or compare employment increases in firms that knew about the subsidies with those that were not aware of them (Perloff and Wachter, 1979; Bishop, 1981). The latter approach is problematic because firms with growing employment have a greater incentive to learn about the program. More recent non-experimental studies use differences in (changes in) regional availability of subsidies (Blundell et al., 2004; Frölich and Lechner, 2004; Forslund et al., 2004; Schmid, 1979). The results of these studies critically hinge on the assumption that the variation in the availability of subsidies is determined exogenously.

More similar to our approach, Katz (1998) uses a natural experiment to assess the effect of hiring subsidies on unemployment durations. He examines a policy change that made economically disadvantaged 23-24 years olds ineligible to a major U.S. wage subsidy program, the Targeted Jobs Tax Credit (TJTC), while those aged 18-22 years maintained eligibility. A so called "difference-indifferences-in-differences" estimator is applied which, in addition to time and age groups, is based on the differences between disadvantaged and nondisadvantages youths. A drawback of this study is that the data set used, the March Current Population Survey (CPS), only includes information on the labor market status for one day per year. If labor market participants in a certain age group have shorter employment spells than others, there may be distortions in the observed employment patterns. Moreover, as mentioned by Katz (1998), the estimated modest positive employment effects may be overshadowed by the elimination of the TJTC subsidy for a second year of employment a year earlier.

4 A number of studies compare the effectiveness of hiring subsidies with other programs. Heckman et al. (1999) conclude that the employment impact of different active labor market policies is similar and small. Martin and Grubb (2001) and Sianesi (2003) stress that hiring subsidies paid to private employers have a greater impact on employment than public training programs or job creation schemes. However, these favorable assessments may partly be due to possible overestimation of the employment effect by the matching estimator, as discussed above. 
Van Reenen (2004) also uses a natural experiment approach to evaluate the British New Deal for Young People. After receiving job seeker allowance for six months, 19-24 year old unemployed individuals are given a choice between four options: full-time education or training, a job for six months with a voluntary sector employer, a job with the Environmental Task Force, or a subsidy to a prospective employer for six months plus training. Van Reenen estimates the combined effect of all measures by calculating the differences in the outflows from unemployment between periods, age groups and pilot and non-pilot areas. The results - an increase in the monthly job finding probability by about 20 per cent - are robust with respect to the control group chosen and the inclusion of further controls. The results may be overestimated because they may contain program introduction effects and the effects of the individual measures cannot be distinguished. However, the robustness of the results with respect to the duration of new jobs, the kind of job, the age definitions of treatment and control group and the presence of Ashenfelter's dip is carefully checked.

The natural experiment approach used in this paper extends the ones by Katz (1998) and Van Reenen (2004) in several respects. First, we use spell data with daily frequency. This allows us to see how the employment effects of hiring subsidies evolve over time. Second, treatment and control groups are very similar in age, which raises the credibility of the identifying assumptions of the difference-in-differences estimator. Third, we compare results from two contrary natural experiments and check their consistency. Fourth, we provide evidence for deadweight effects. Finally, we offer extensive robustness checks of our estimates.

\section{Description of hiring subsidies in Germany}

In this paper, we are concerned with the Integration Supplement (Eingliederungszuschuss, EGZ), a hiring subsidy paid to the employer over a fixed period of time. The Integration Supplement has been available from 1998 to support the hiring of workers with unfavorable labor market characteristics. With a total spending volume of 0.9 to 1.3 billion $€$ per year, it is one of the major active labor market programs in Germany, accounting for roughly 5 per cent of all active labor market spending.

Until 1998, there were several parallel programs. Since 1998, all subsidy programs other than the newly introduced Integration Supplement (EGZ) have 
been gradually phased out. 5 The number of participants increased markedly after 1998 and reached a high in February 2003, when more than 160,000 workers were employed in a contract supported by the EGZ (see Figure 1). As in other active labor market programs, the number of participants has declined more recently.

The EGZ is paid to the employer as a percentage of standardized labor costs defined as the gross wage rate (as laid down in collective agreements) plus a lump-sum allowance for employer contributions to social security. If the employment relationship is terminated before a minimum period after the expiration of the subsidy, the employer is legally obliged to refund parts of the subsidy, although local employment agencies often refrain from enforcing this requirement.

There is no legal claim to EGZ either by the worker or the employer. Rather, placement officers at the local employment agencies decide on program participation. The purpose of the EGZ is to facilitate hiring of persons with individual disadvantages on the labor market. In 1998, three variants of the EGZ were defined: EGZ while adapting to the new job, EGZ for workers with placement difficulties and EGZ for older workers. Initially, the law defined older workers as workers above the age of 55 , but this limit was reduced to 50 years.

Benefit duration and volume differ for these groups. According to the rules applying during the observation period, older workers were eligible to the highest amount of subsidies. The regular subsidy was defined as 50 per cent of standardized labor costs, paid over an interval of 24 months. If a specific reason could be provided, the amount could be increased to 70 per cent and the duration of payment extended to at most 70 months (the share of subsidy payments in wage costs had to be reduced after 24 months, however). In general, German hiring subsidies are generous compared to subsidies in other countries (Bell et al., 1999).

Concerning the eligibility of older workers to the EGZ subsidies, two major changes were made in 2002 and 2004. Both of them are used as natural experiments in this paper. Before January 1st, 2002, the EGZ for older workers could only be paid in case of hiring of a person who had been either long-term

5 An exception is the Integration Supplement for Start-up Companies (Eingliederungszuschuss bei Neugründung, EZN). 
unemployed 6 or had been registered as unemployed for at least six months during the 12 months before hiring. From January 1st, 2002, hiring of all unemployed workers above the age of 50 could potentially be subsidized by the EGZ.

As part of a legislative package known as "Hartz laws" in Germany, the separate EGZ program for older workers was ended by January 1st, 2004. Depending on local employment agencies' policies, workers below this threshold had now the same chances to be supported by EGZ subsidies. As a consequence, the share of individuals aged between 50 and 55 among all workers subsidized by EGZ declined from 19.1 to 13.3 per cent between 2003 and 2005 (ZEW, IAB and IAT, 2005: Statistical Appendix).

Importantly for the identification of causal effects, these changes were the only ones affecting the age groups at the time. A change did occur with the introduction of the Income Safeguarding Program (Entgeltsicherung, Egs), taking effect from January 1st, 2003. Since the program applies to all workers aged 50 or above, the age limit is the same as for the EGZ subsidies. However, the date of introduction differs from the changes under consideration here. Regarding other changes in policies affecting older individuals, both the age threshold and the introduction date differ from the change to the EGZ subsidy.

An implementation study based on case studies from 10 local employment agencies and 84 telephone interviews with company representatives concludes that there is substantial scope for decision-making at the local level concerning the allocation of the subsidy to a particular company for employment of a particular worker, the amount and the duration of benefits (ZEW, IAB and IAT, 2005). In the majority of cases, an initial contact between a worker and an employer already existed and the employment agencies reacted to the company's inquiries about whether the employment of a particular worker could be subsidized. In these cases, the suspicion that subsidies are ineffective for hiring is high. Moreover, about half of the companies who had received EGZ in the past

6 The definition of long-term unemployment is contained in $\S 18$ of the German Social Code, Volume III: "(1) The long term unemployed are individuals unemployed for at least one year. (2) As regards benefits of active labor market policies, the following interruptions of unemployment are not considered within a five-year period: 1. periods in active labor market programmes, 2. periods of sickness or maternity leave, 3. periods used for child-rearing or care for dependants, 4. employment or self-employment up to a duration of six months, 5. periods during which employment was legally impossible, and 6. short interruptions without further evidence." (own translation) 
responded that their hiring behavior had not been affected by the EGZ. Overall, the implementation study strongly confirms the notion that deadweight effects are a major issue for the effectiveness of German hiring subsidies.

\section{The data}

The evaluation is based on the Integrated Employment Biographies (IEB), an administrative data set assembled and provided by the German Federal Employment Agency. Detailed information on a random sample from the IEB can be found in Hummel et al. (2005). Since our study was conducted as part of an official evaluation of the "Hartz laws", we had access to the population of individuals entering unemployment.

The IEB are composed of the following four separate data bases:

- The Employment Register $(\mathrm{BeH})$ is composed of the compulsory reports to the public pension system of German companies on the start, change or end of all employment relationships. Different forms of employment, such as regular work, marginal employment or employment in vocational training schemes, can be distinguished.

- The Benefit Claimants Register (LeH) unifies data on the receipt of unemployment benefit or (former) unemployment assistance and the subsistence allowance paid in cases of sickness.

- The Program-Participants Comprehensive Data Base (MTG) provides information on participation in active labor market programs, such as subsidized employment (including EGZ), training schemes, the bridging allowance for start-up companies by the unemployed and other programs.

- The Job Applicant Files (BewA) is the most comprehensive data base on the characteristics of all registered job seekers. It contains all statistical information available to job centers when placement decisions are made.

All of the information contained in the data set is collected daily. From the information on age, date of entry into unemployment and (for the 2002 case) previous unemployment durations, the data set of unemployment spells is constructed. Unemployment is defined as registered unemployment, irrespective of unemployment benefit receipt. To classify individuals as long-term or shortterm unemployed in the legal sense, we trace previous employment states in the 
data. The complexity of the legal definition of long-term unemployment can only be approximated. However, the approximation seems to work well.7

Originating from different sources, the data are not always consistent. In particular, we found that not all workers found to be subsidised by EGZ in the MTG are reported to be in regular employment according to the BeH. In these cases, we have given precedence to the information from the MTG since the employer may have reported a hiring to the pension insurance belatedly. In cases of parallel spells of employment and unemployment or benefit receipt, we have given precedence to the latter piece of information.

In counting episodes as employment, and, hence, constructing exit from unemployment, we exclude participation in active labor market programs of other kinds, such as Employment Creation Schemes (ABM), Structural Adjustment Measures (SAM) or training programs. Individuals may be in subsidized employment as well as participate in other programs. If participation in these programs differs according to age groups, this may distort the outcome measure unless employment spells that coincide with program participation are eliminated. Moreover, employment effects of hiring subsidies can only be isolated from spells that do not coincide with other programs. Therefore, all employment spells starting at the same date (with two days tolerance) as a spell in active labor market programs are eliminated from the data.

\section{Estimation approach}

To estimate the causal effect of treatment, we use the difference-in-differences estimator, based on the extension of eligibility to individuals with short unemployment durations in 2002 and the integration of the EGZ subsidy for older workers into the general EGZ framework in 2004. In both cases, the control group consists of workers below 50 years of age and, hence, never eligible to the EGZ for Older Workers. The change in the estimated transition probabilities between the two time periods is determined for the treatment and the control group and the difference between both changes is calculated. An alternative would be regression discontinuity design based on the age threshold. However, there are other reasons why transitions to employment could make a step at the

7 There are only 11 cases of individuals receiving the EGZ for Older Workers who were ineligible according to our definition of long-term unemployment. Moreover, in most cases, individuals were ineligible according to any legally possible definition of long-term unemployment. 
age threshold, such as the Income Safeguarding Program (Egs) and, possibly, hiring policies in the public and private sector.

Continuous-time duration models are used to specify the outcome variable. Hence, we avoid choosing an observation date arbitrarily, which could be non-representative for the whole observation period. Moreover, duration analysis allows us to assess how the employment effect evolves over the 180 days during which unemployment spells are observed. The failure event is taken to be a transition into employment (in the definition given in the previous section).

In order to avoid length-bias, the sampling principle in our study is flow sampling. We observe a three months entry cohort of unemployed persons over a period of up to 180 days of their unemployment spell (see Figure 2). In the first natural experiment, we use data on all persons entering unemployment between April 1st and June 30th in either 2001 (pre-change) or 2002 (after the change). In the second natural experiment, we include individuals becoming unemployed between April 1st and June 30th, 2003 or 2004, respectively. All spells are treated as right censored after 180 days of unemployment. The reason is that, in the first natural experiment, individuals in the treatment group with more than six months of unemployment duration had been eligible for the subsidy even before the policy change. In the second case, data availability limits the period during which transitions into employment can be observed.

Four distinct groups are defined: workers aged 50 to 50 plus six months at the time of entering unemployment and workers aged between 49 and 49 plus six months, both before and after the program change. 8 A difference between the two natural experiments is that in the first case, individuals with previous unemployment durations above the legal threshold of long-term unemployment are excluded because they are not affected by the policy change.

We use the time varying unconditional effect obtained from KaplanMeier-Survivor functions. The Kaplan Meier survivor function (DD) estimates the probability of remaining in unemployment $\tau$ days after the beginning of the unemployment spell. The DD effect is defined as:

$$
D D(\tau)=\left[\hat{S}_{h, t=1}(\tau)-\hat{S}_{h, t=0}(\tau)\right]-\left[\hat{S}_{k, t=1}(\tau)-\hat{S}_{k, t=0}(\tau)\right] .
$$

Here, for example, $\hat{S}_{h, t=1}(\tau)$ is the survivor function (the estimated probability of remaining in unemployment) in the treatment group at $t=1$, where $t$ refers to the

8 The effects of changes in the definition of the groups are discussed in section 8 . 
periods before (0) and after (1) the change. The subscripts $h$ and $k$ indicate membership of the treatment and control groups. 9

Equation (1) implies that the causal effect is estimated for every point in time $\tau$. Accounting for changes in the effect of the subsidy is important because subsidies may not be disbursed immediately after entry into unemployment. Alternatively, they could accelerate hirings such that the effect is larger at the start than towards the end of the observation period. To calculate standard errors, we use a bootstrapping procedure drawing 300 resamples. For each resample, all effects are recomputed. A 95 per cent confidence interval is defined using the 0.025 and 0.975 quantiles of all realizations of the effects for every single day. That is, pointwise confidence intervals are constructed.

To estimate deadweight effects, we compare the estimated effects of the program changes on exit to employment with the corresponding change in the starts of subsidy payments. If both are equal, all subsidized hirings are additional and there are no deadweight effects. If the latter effect exceeds the former, some of the subsidized hirings are not additional in the targeted group of workers. Since the distinction between both exit states requires a competing risks framework, we use the cumulative incidence function instead of the Kaplan-Meier estimate:

$$
D D_{j}(\tau)=\left[\bar{F}_{j, h, t=1}(\tau)-\bar{F}_{j, h, t=0}(\tau)\right]-\left[\bar{F}_{j, k, t=1}(\tau)-\bar{F}_{j, k, t=0}(\tau)\right]
$$

where $\bar{F}_{j}(\tau)=\operatorname{Pr}(T \leq \tau, J=j)$ is the cumulative incidence function, $j$ is the destination state and $T$ is the exit date. Unlike Kaplan-Meier estimates calculated for the risks separately, the risk-specific $\bar{F}_{j}(\tau)$ sum to the total cumulative incidence functions for all risks taken together (Kalbfleisch and Prentice, 2002: 252). The destination states $j$ are exit into a job subsidized by EGZ and exit into unsubsidized employment. If deadweight effects are complete, the difference-indifferences estimations of the cumulative incidence functions into both types of work should have the same magnitudes but opposite directions. If there are no

9 A generalization of the difference-in-differences estimator that takes into account heterogeneity in the distribution of unobservables between treatment and control groups has been proposed by Athey and Imbens (2006). Since we have chosen treatment and control groups as narrow age groups that are very close to each other, we regard the issue of unobserved heterogeneity (and indeed, observed heterogeneity as well, see section 7) as not important to our application. Moreover, the Athey and Imbens estimator is not directly implementable to continuous duration models. 
deadweight effects, all new employment subsidized by the EGZ should be additional in the group of subsidized workers. Hence, unsubsidized exits should be unaffected.

\section{Results}

Before the employment effects of the change in eligibility conditions are explored, we first track their effects on the number of subsidized employment relationships in the data. If the share of subsidies disbursed remained unchanged, any changes in employment could not be attributed to the legal changes in 2002 and 2004. The numbers in Table 1 represent the number of exits into subsidized employment over the number of spells. They refer to all EGZ subsidies, whether specifically designed for older workers or for other labor market groups. The table shows that the change in admission criteria in 2002 resulted in a strong increase in the share of supported workers in the treatment group. For the year 2004, we observe the opposite effect - the share of subsidies for the treatment group was reduced more strongly than that of the control group. Hence, the legal changes did have a considerable effect on actual participation in the program in both cases.

To give an indication of the probability of exit into employment, table 2 contains the Kaplan-Meier survivor function up to 180 days after entry into unemployment in the four groups and each of the two natural experiments. Owing to the fact that the long-term unemployed are excluded in 2001/2002, the survivor function is lower for these years. After about half a year, between 18 and 28 per cent of the unemployed had taken up employment. The probability of exit is slightly lower for the older age group. However, the differences depend on the year in which they are measured, and the confidence bands overlap in most cases. Therefore, the differences between treatment and control group are small.

On the basis of the estimated survivor function, we calculate the DD estimators for all durations $\tau$ according to equation (1). Figures 3 and 4 show the results. Regarding the extension of eligibility in 2002, the estimated effect on survival in unemployment is negative as expected. Conversely, the end of the separate program for older workers in 2004 led to an increase in the probability of remaining unemployed, which is also in line with expectations. However, the effects are not monotonic and, judged by the bootstrapped confidence intervals, not statistically significant. 
Separate estimations for four population groups, men and women in East and West Germany, show striking differences (Figures 5 and 6). Women in East Germany are the only group where there is any significant effect in 2002. The DD-estimate is large: at $\tau=180$, exit rises by 6 percentage points. All other groups did not experience any changes in re-employment probabilities. Regarding the program change in 2004, the effects also differ between men and women. With up to three percentage points, the effects on women are again relatively large. However, they are significant only for East German females, and only for parts of of the duration. Contrary to expectation, the estimated effects on West German males indicate an improvement in the probability of exit from unemployment. However, the effect is not significant.

The time-varying nature of the estimated effects also permits an assessment concerning the relevance of Ashenfelter's dip (Ashenfelter, 1978). There is a possible anticipation effect concerning the eligibility to subsidized hiring after six months of unemployment in the period before the policy change in 2002. In the expectation that subsidies would soon be available, employers may have been reluctant to hire workers shortly before the start of eligibility (i.e., shortly before they became long-term unemployed). This may result in a low exit rate before the policy change in the treatment group and, therefore, to a spurious difference-indifferences effect close to the end of the 6-months period. However, the time pattern of the estimated effects of the subsidy does not exhibit an increase towards the end of the observation period. Hence, Ashenfelter's dip does not seem to be an issue here. 10

Next, we turn to the magnitude of the deadweight effects. The small size of the effects on employment does not necessarily speak against the effectiveness of the program provided that the number of subsidy starts is equally low. Figures 7 and 8 show difference-in-differences based on the cumulative incidence functions, i.e. the $\mathrm{DD}_{\mathrm{j}}$ effects according to equation (2), for all groups taken together and for the natural experiments taking place in 2002 and 2004. Note that compared to the previous graphs, the interpretation of the curve differs: a positive number means an increase in the probability of exit, not of survival in unemployment. The graphs show that both changes to the legal eligibility criteria had

10 A second anticipation effect concerns unemployed persons at the age threshold of eligibility. Being targeted at workers above 50, program design may induce firms to postpone hiring of an individual until his or her 50th birthday. We take up this point in the re-definition of age groups (see section 7 below). 
relatively large effects on subsidized employment in the treatment group. Measured as shares among all unemployed persons, they amount to a two percentage point increase in 2002 and a one to two percentage point decline in 2004. This is much larger than the DD effect on employment. The difference between the two consists of exits into unsubsidized employment, which are influenced negatively by the availability of subsidies. Hence, deadweight effects dominate.

Separate analyses for the four population groups (not included here) show that unsubsidized hirings decline in the same proportion as subsidized hirings occur among all groups except East German women. Unsubsidized hirings are unaffected among East German women. The magnitudes of the estimated employment effects are in all cases reasonable given the amount of subsidies paid out. In particular, the estimated employment effect should not be larger than the effect of the changes in eligibility on subsidies disbursed in the treatment group.

Overall, the results point at the absence of any effects of the subsidy program on exits from unemployment in most groups of the population. They suggest that employers reduced unsubsidized hiring by almost the same amount as they received subsidies. However, consistently positive effects are found for East German women. The chances of leaving unemployment among East German women improved vis-à-vis the control group when eligibility was extended in 2002, and they deteriorated when preferential treatment was abolished in 2004. However, even here the employment effect is significant only for parts of the duration. This points to the advantage of using a duration model instead of a binary model estimated at a specific point of time in the unemployment duration. Differences in the results according to population groups are by no means implausible, since unemployment rates are different within these groups and the composition of unemployed workers differs between them. There is ample evidence that the effects of active labor market policies depend on the labor market situation.

\section{Robustness}

\section{Adjusting for heterogeneity}

Changes in the composition of the groups compared in the DD estimation between the observation periods could potentially bias the results. Therefore, in addition to the estimators already discussed, we use estimators that condition on observed heterogeneity. The covariates used to reduce observed differences 
between treatment and control group relate to the family situation (single, married or living with a partner, or lone parent), the qualification of the worker, previous work experience, and education. They are summarized in Table 3 separately for the treatment and the control groups. With the exception of family situation, both groups of individuals do not exhibit substantial differences in composition. 11

An approach that combines the time variability of the unconditional DD estimator with the control for covariates is an estimation of the causal effect as difference of implicit baseline hazard rates. We first estimate a partial likelihood Cox proportional hazard rate model:

$$
\lambda(\tau)=\lambda_{0}(\tau) \cdot \exp \left(z_{i}^{\prime} \gamma\right)
$$

The results are contained in table A1 in the appendix. The coefficients of the control variables influence employment chances comparable to other studies (Knight, 2002; Forslund et al., 2004; Caliendo et al., 2005). On the basis of the estimations, we then estimate the baseline survivor function $\hat{\bar{S}}_{0}(\tau)$ for the treatment and control group and for the two time periods. From this, we derive the conditional DD effect analogously to equation (1):12

$$
D D^{C}(\tau)=\left[\hat{\bar{S}}_{h, t=1}(\tau)-\hat{\bar{S}}_{h, t=0}(\tau)\right]-\left[\hat{\bar{S}}_{k, t=1}(\tau)-\hat{\bar{S}}_{k, t=0}(\tau)\right] .
$$

As before, a negative effect means an increase in the exit rate into employment since the effect rests on the baseline survivor curves.

From Figures 9 and 10, the differences between conditional and unconditional estimates can be compared. While the results do not change qualitatively, the $\mathrm{DD}^{\mathrm{C}}$ effect has a smaller size than the unconditional DD effect over some of the duration for the 2002 results. In particular, the effect on survival is smaller towards the end of the observation period. Detailed results for the four population

11 There is, however, a break between 2001 and 2002 in the share of individuals with previous job experience which is likely to be due to a change in the definition of the variable in the original data.

12 Another conditional DD effect can be obtained from the interaction term between treatment indicator and the time dummy indicating before and after the policy change. This measure depends on the assumption that the probability to exit into unemployment is constant during the observation period. We use the estimator based on the baseline survivor curve solely because it can be better compared to the unconditional estimates. 
groups, however, show that the effect on East German women is hardly weakened. Thus, the conclusions to be drawn from the results remain unchanged. For the 2004 natural experiment, there are no noticeable changes between conditional and unconditional results.

Widening the age groups

With only six months maximum difference in birth dates, age groups were chosen to be narrow in the estimations discussed so far. This is necessary because the labor market situation may evolve differently for different age groups. For instance, employers may be more hesitant to hire older workers as compared to younger workers in times of economic improvement because employment protection is often stricter for older workers, age being one criterion used in unjust-dismissal litigation and for social selection in cases of redundancies in Germany. For this reason, the ages of individuals in the treatment and control groups should not be too distant.

A disadvantage of narrow groups is that the importance of crowding-out effects between treatment and control group may be higher (Van Reenen, 2004). Therefore, we also calculated the effects using broader age bands. In particular, we extend the treatment groups to individuals between 50 and 51 years, and the control group to workers aged 48 and six months to 49 and six months. The extension of the age group also checks for a second version of Ashenfelter's dip (see section 6). There is a possibility that individuals well after their 49th birthday will not be hired if employers expect that a subsidy can be obtained after their 50th birthday. Thus, by concentrating on individuals aged 49, we may overestimate the effect of eligibility.

Results are contained in Figures 11 and 12. There are some changes over parts of the duration. However, exit probabilities among the narrow and wider age groups are virtually identical towards the end of the observation period. Thus, we conclude that our results are robust to changes in the definition of treatment and control groups.

\section{Conclusions}

In this study, we have used a natural experiment design to assess whether hiring subsidy programs lead to earlier exit from unemployment to employment in the group of eligible persons as compared to the situation in which no subsidies are available. We base our study on two changes in the eligibility criteria: the first 
policy change extended potential program participation to older workers unemployed for less than six months. The second policy change ended specific treatment of older unemployed above 50 years of age and made younger and older individuals equally eligible for subsidies.

We use a difference-in-differences estimator to examine the causal effect of eligibility. This estimator compares the change in the survival in unemployment during the first 180 days of unemployment of the treatment group in comparison to a control group of unemployed just below the age of eligibility. We show that the broadening of eligibility in 2002 increased the likelihood of exiting unemployment only for East German women. Consistent with this finding, the end of specific treatment of older workers in 2004 reduced the causal employment effect in this group.

The results from an implementation study and evidence from previous literature strongly suggest the presence of deadweight effects. To estimate deadweight effects, we compared the number of estimated additional employment relationships to the estimated number of additional subsidies disbursed. The absence of positive employment effects for males suggests that the observed increase in subsidized employment is absorbed by deadweight effects. Conversely, as regards East German women, the effects on subsidy take-up and on employment are very similar in magnitude. Hence, deadweight effects are not important in this group. Robustness checks such as controlling for covariates and different definitions of treatment and control groups lead to similar results.

Clearly, these results constitute only a first step towards a comprehensive evaluation of hiring subsidies. There remains the question of the persistence of the employment relationships that were initially subsidized. A major difficulty here is to form a suitable control group for program participants. Moreover, it is quite possible that additional employment merely substitutes employment cuts in other population groups. Since the absence of these substitution or displacement effects cannot be ascertained in a microeconometric study of individual workers, analyses at the firm or the regional level remain useful complements.

\section{References}

Ashenfelter, O. (1978) Estimating the effect of training programs on earnings, Review of Economics and Statistics, 60, 47-57.

Athey, S., G. Imbens (2006), Identification and Inference in Nonlinear Difference-in-Differences Models, Econometrica 74, 431-497. 
Bell, B., R. Blundell, J. van Reenen (1999), Getting the Unemployed back to work: The role of targeted wage subsidies, International Tax and Public Finance 6, 339-360.

Bishop, J. (1981), Employment in Construction and Distribution Industries: The Impact of the New Jobs Tax Credit, in S. Rosen (ed.), Studies in Labor Markets, Chicago: University of Chicago, 209-246.

Blundell, R., M. Costa Dias, C. Meghir, J. van Reenen (2004), Evaluating the Employment Impact of a Mandatory Job Search Program, Journal of the European Economic Association, 2 (4), 569-606.

Caliendo, M.; R. Hujer; S. Thomsen (2005), The employment effects of job creation schemes in Germany: a microeconometric evaluation, IZA Discussion Paper 1512, Bonn.

Cockx, B., C. Göbel (2005), Subsidized employment for young long-term unemployed workers - an evaluation, mimeo, Université de Louvain, Louvain-la-Neuve.

Forslund, A.; P. Johansson; L. Lindqvist (2004), Employment subsidies - A fast lane from unemployment to work?, IFAU Working Paper 2004:18.

Frölich, M. and Lechner, M. (2004), Regional Treatment Intensity as an Instrument for the Evaluation of Labour Market Policies, IZA Discussion Paper 1095, Bonn.

Hamersma, S. (2005), The Effects of an Employer Subsidy on Employment outcomes: A Study of the Work Opportunity and Welfare-to-Work Tax Credits, Institute for Research on Poverty Discussion Paper 1305-05, Gainesville.

Heckman, J., R. Lalonde, and J. Smith (1999), The Economics and Econometrics of Active Labor Market Policies, in O. Ashenfelter and D. Card (eds.), Handbook of Labor Economics 2, Amsterdam: Kluwer, 1865-2097.

Hollenbeck, K.M. and R. J. Willke (1991), The Employment and Earnings Impacts of the Targeted Jobs Tax Credit, Upjohn Institute for Employment Research.

Hummel, E.; P. Jacobebbinghaus; A. Kohlmann; M. Oertel; C. Wübbeke; M. Ziegerer (2005), Stichprobe der Integrierten Erwerbsbiographien, IEBS 1.0, FDZ Datenreport, Bundesagentur für Arbeit, Nürnberg.

Jaenichen, U. (2002), Lohnkostenzuschüsse und individuelle Arbeitslosigkeit, Mitteilungen aus der Arbeitsmarkt- und Berufsforschung, 35, 327-351. 
Katz, L. (1998), Wage Subsidies for the Disadvantaged, in R. Freeman and P. Gottschalk, eds., Generating Jobs: How to Increase Demand for LessSkilled Workers, Russell Sage, New York, 21-53.

Knight, G. (2002), Evaluation of the Australian Wage Subsidy Special Youth Employment and Training Program, dissertation, University of Sidney.

Koning, J. de (1993), Measuring the Placement Effects of Two Wage-Subsidy Schemes for the Long-term Unemployed, Empirical Economics, 18, 447468.

Lorenz, E.C. (1988), The Targeted Jobs Tax Credit in Maryland and Missouri: 1982-87, National Commission of Employment Policy.

Martin, J.P. (2000), What works among active labor market policies: Evidence from OECD countries' experiences, in: OECD Economic Studies 30, Paris.

Martin, J.P., D. Grubb (2001), What works and for whom: A review of OECD countries' experiences with active labor market policies, Swedish Economic Policy Review 8, 9-56.

Marx, I. (2001), Job subsidies and cuts in employers' social security contributions: The verdict of empirical evaluation studies, International Labor Review, 140, 69-83.

Meyer, B.D. (1995), Lessons from the U.S. unemployment insurance experiments, Journal of Economic Literature, 33, 91-131.

OECD (1990), Labor Market Policies for the 1990s, Paris.

Orszag, J.M.; D.J. Snower (2003), Designing employment subsidies, Labor Economics, 10, 557-572.

Perloff, J. M., M. Wachter (1979) The New Jobs Tax Credit: An Evaluation of the 1977-78 Wage Subsidy Program, American Economic Review 69, 173179.

Reenen, J. van (2004), Active Labor Market Policies and the British New Deal for the Young Unemployed in Context, in: R. Blundell, D. Card and R. Freeman (eds.), Seeking a Premier Economy, University of Chicago Press, 461-496.

Schmid, G. (1979), The Impact of Selective Employment Policy: The Case of a Wage-Cost Subsidy Scheme in Germany, 1974-75, Journal of Industrial Economics 27, 339-358. 
Sianesi, B. (2003), Swedish active labor market programs in the 1990s: Overall effectiveness and differential performance, IFS Working Paper 02/03.

ZEW; IAB; IAT (2005), Evaluation der Maßnahmen zur Umsetzung der Vorschläge der Hartz-Kommission, Arbeitspaket 1: Wirksamkeit der Instrumente, Modul 1d: Eingliederungszuschüsse und Entgeltsicherung, Bericht 2005 durch den Forschungsverbund Zentrum für Europäische Wirtschaftsforschung (ZEW), Institut für Arbeitsmarkt und Berufsforschung (IAB), Institut Arbeit und Technik (IAT), Mannheim, Nürnberg, Gelsenkirchen. 
Figure 1: Employment contracts subsidized by Integration Supplements

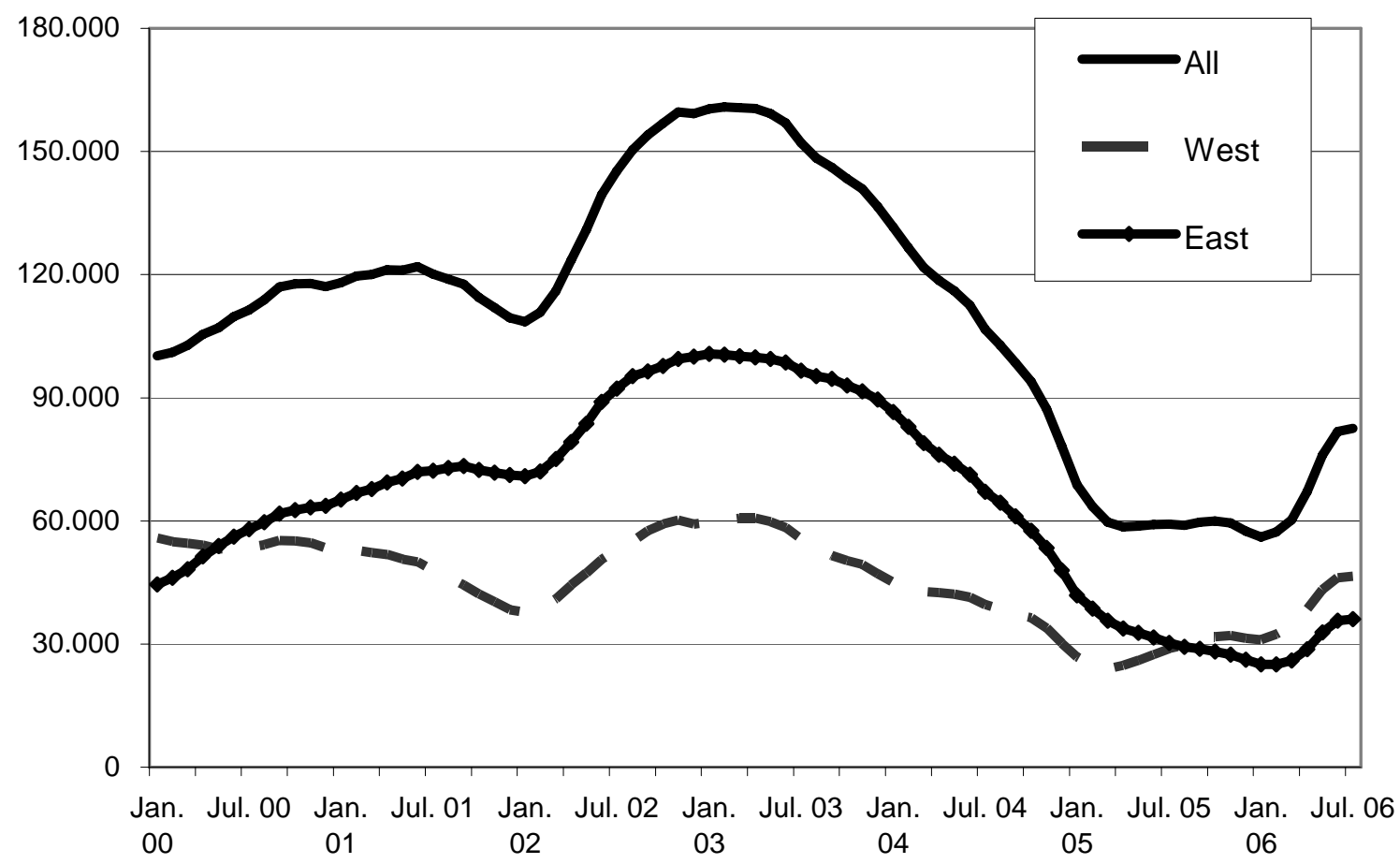

Source: Federal Employment Agency,

http://www.pub.arbeitsamt.de/hst/services/statistik/detail/f.html 
Figure 2: Definition of observation periods

Policy change

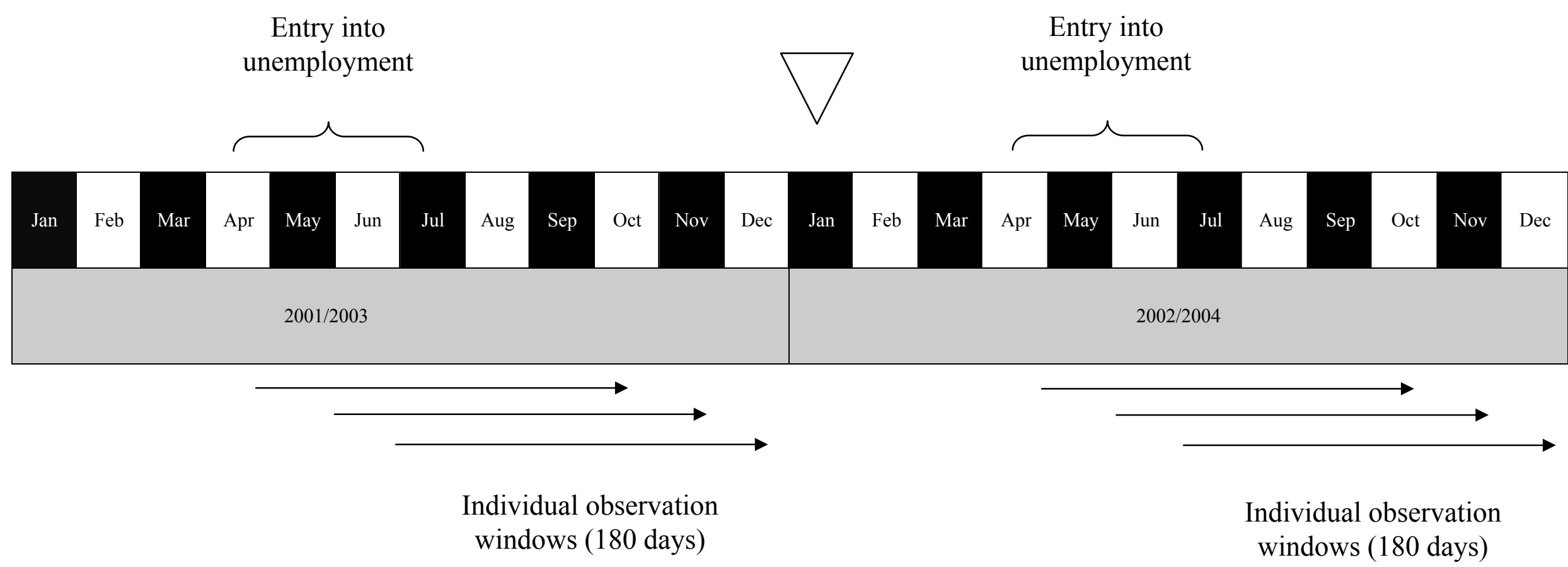


Figure 3: Estimated effect of widening eligibility, 2002

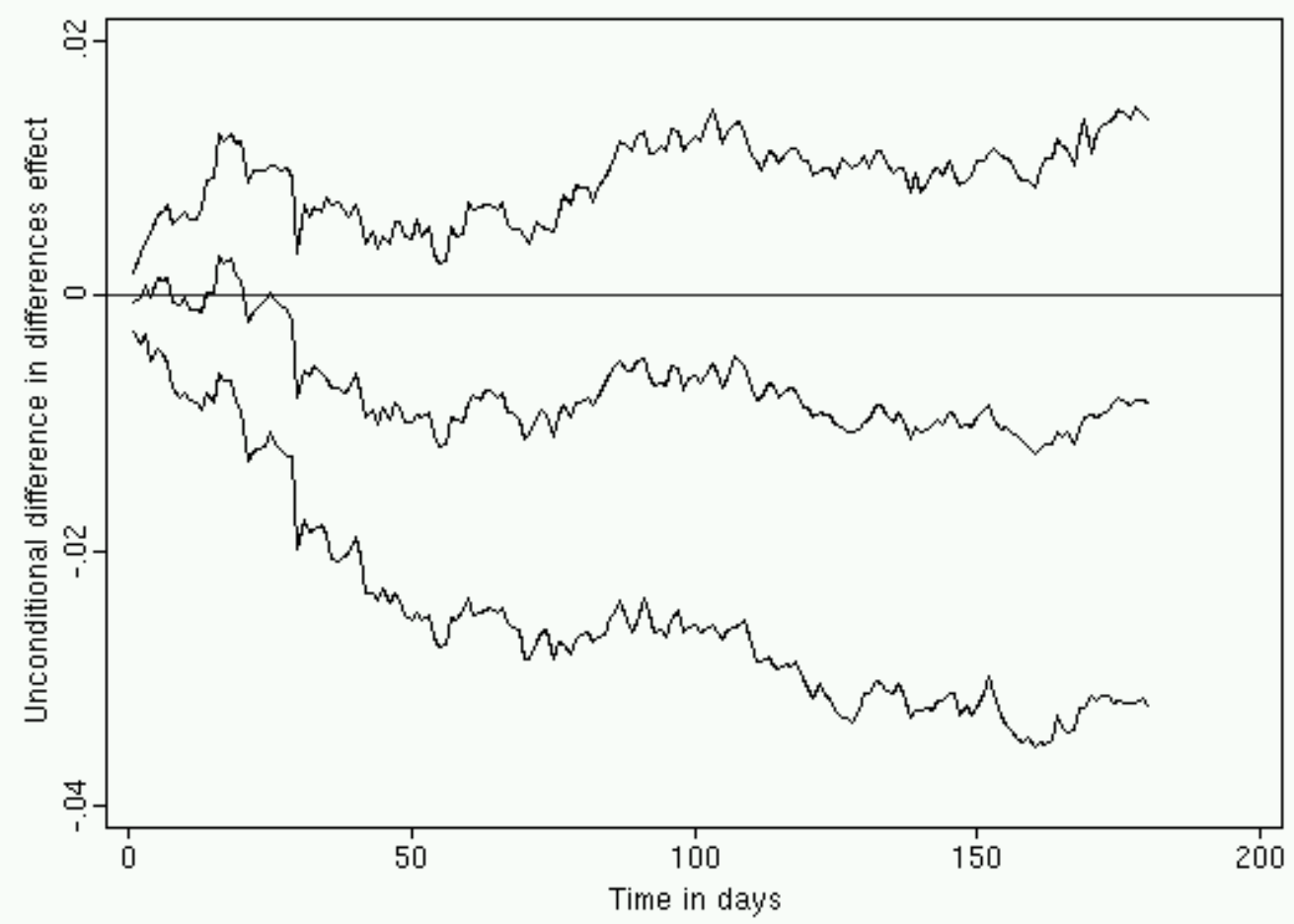

Note: upper and lower curves are .95 confidence bands obtained by bootstrapping.

Figure 4: Estimated effect of ending the program, 2004

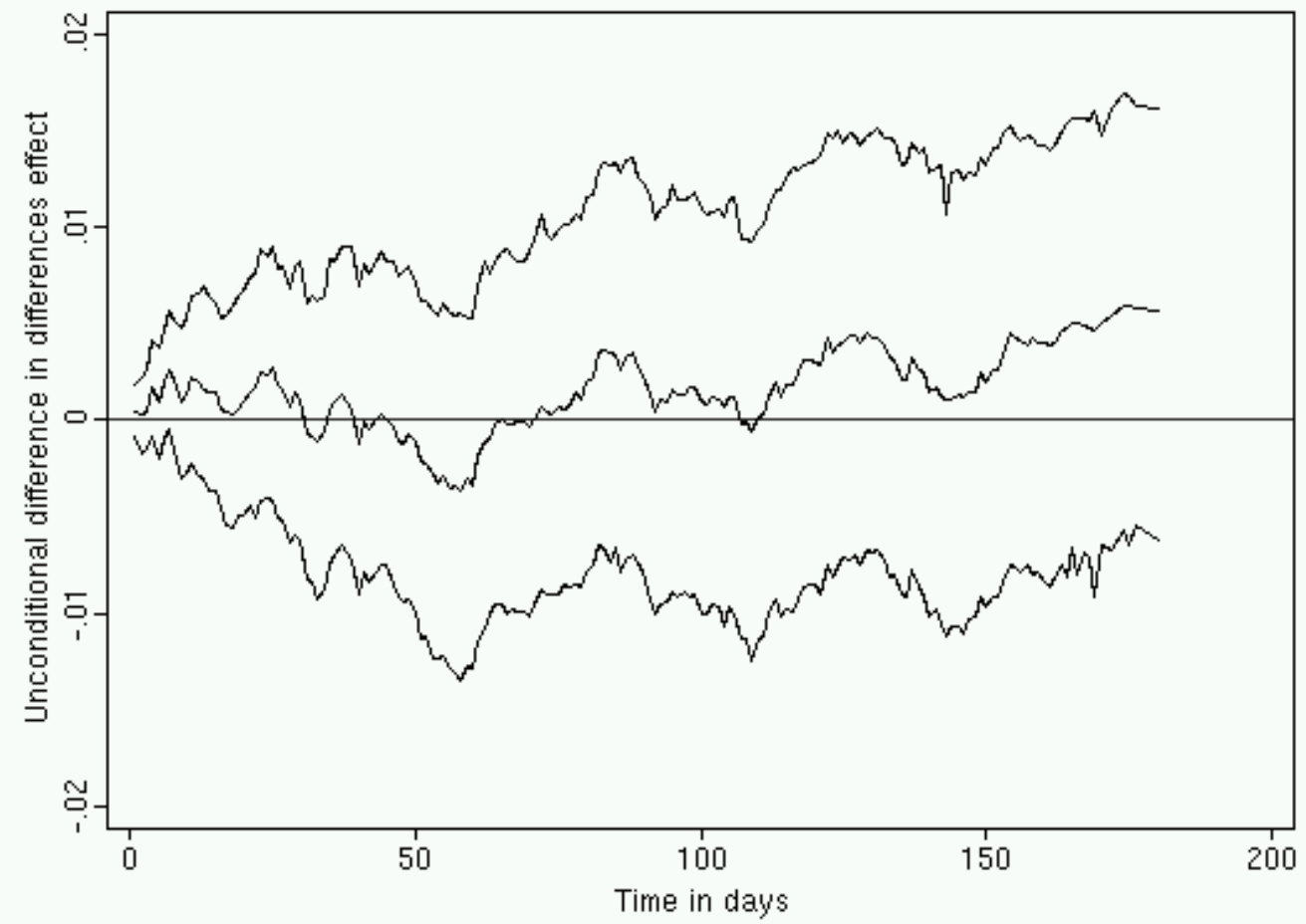

Note: upper and lower curves are .95 confidence bands obtained by bootstrapping 
Figure 5: Separate estimations for population groups, 2002

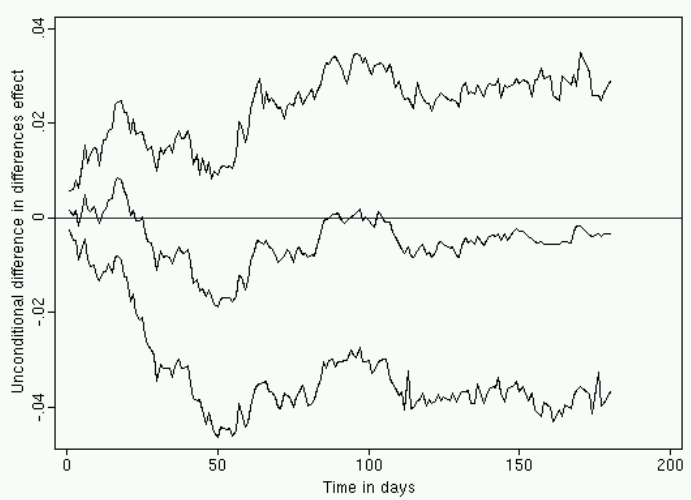

(a) Men, West

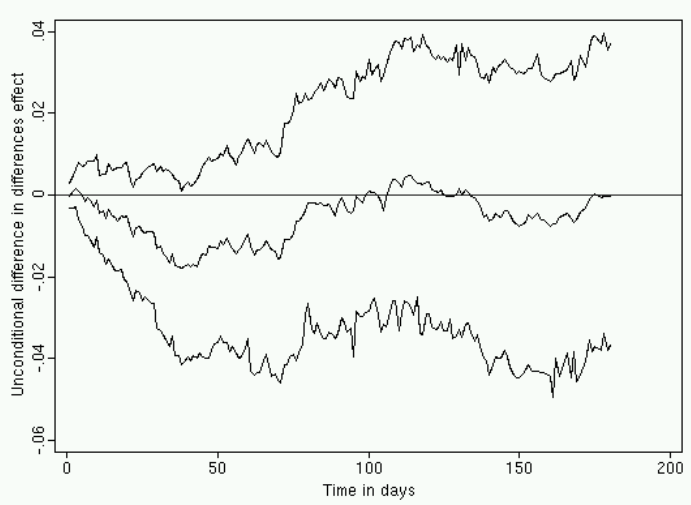

(c) Women, West

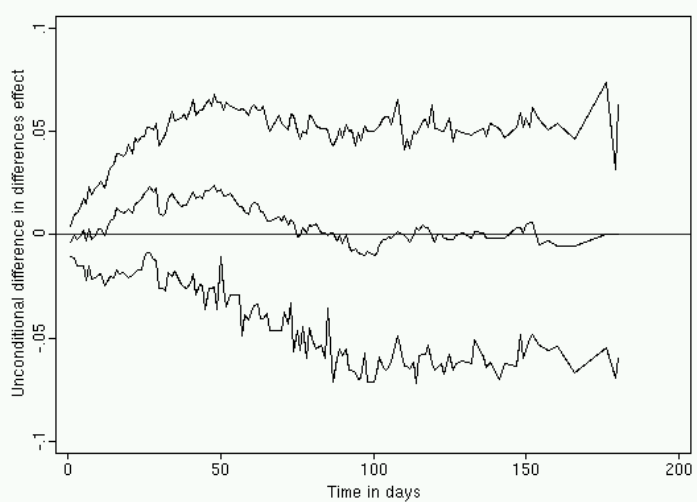

(b) Men, East

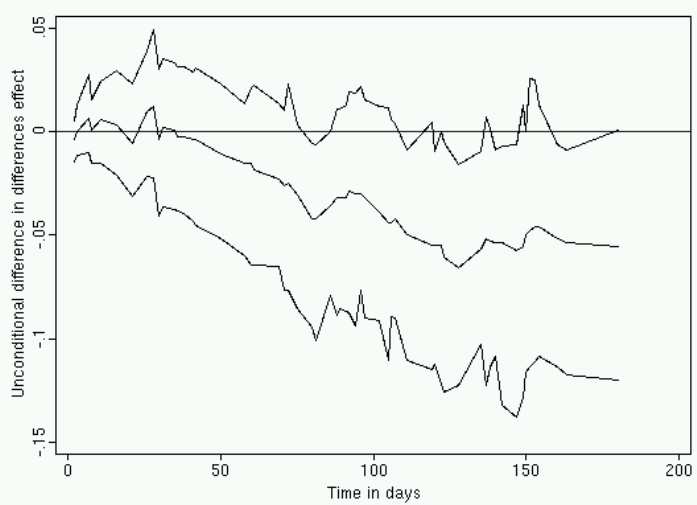

(d) Women, East

Note: upper and lower curves are .95 confidence bands obtained by bootstrapping. 
Figure 6: Separate estimations for population groups, 2004

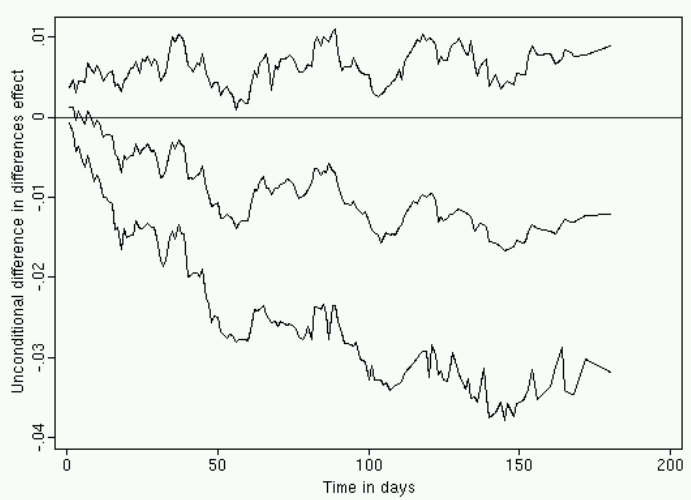

(a) Men, West

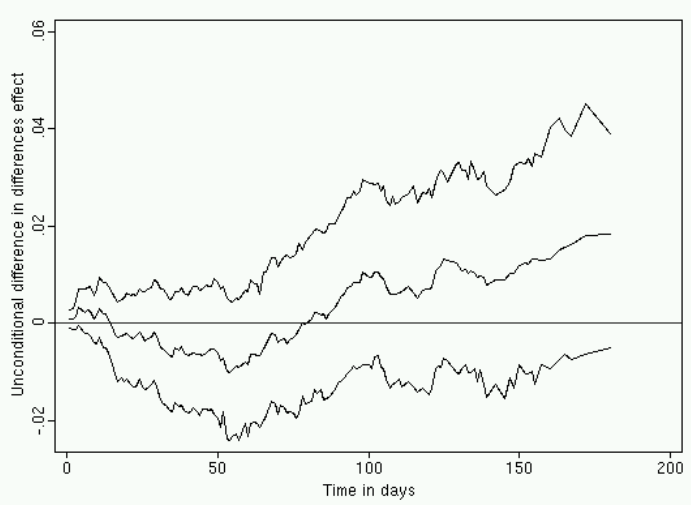

(c) Women, West

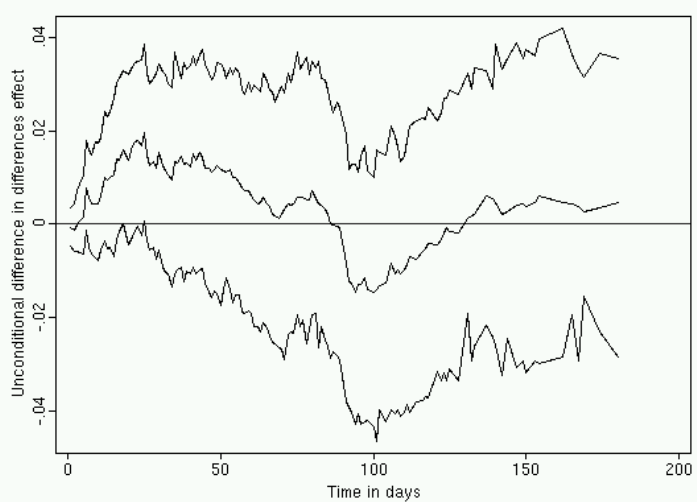

(b) Men, East

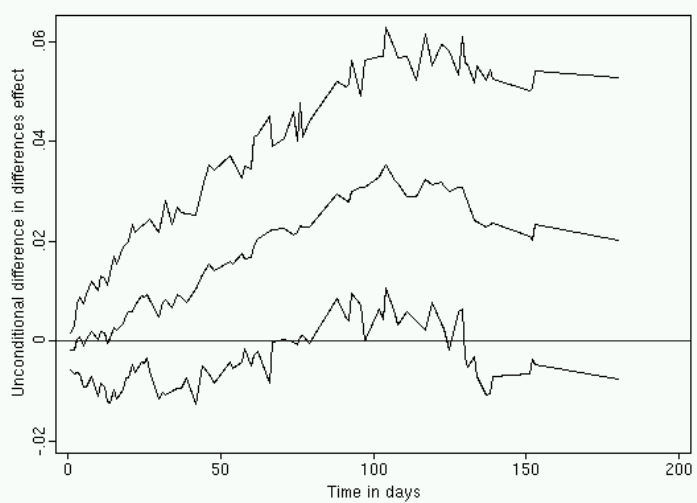

(d) Women, East

Note: upper and lower curves are .95 confidence bands obtained by bootstrapping. 
Figure 7: Cumulative incidence function results for the 2002 experiment

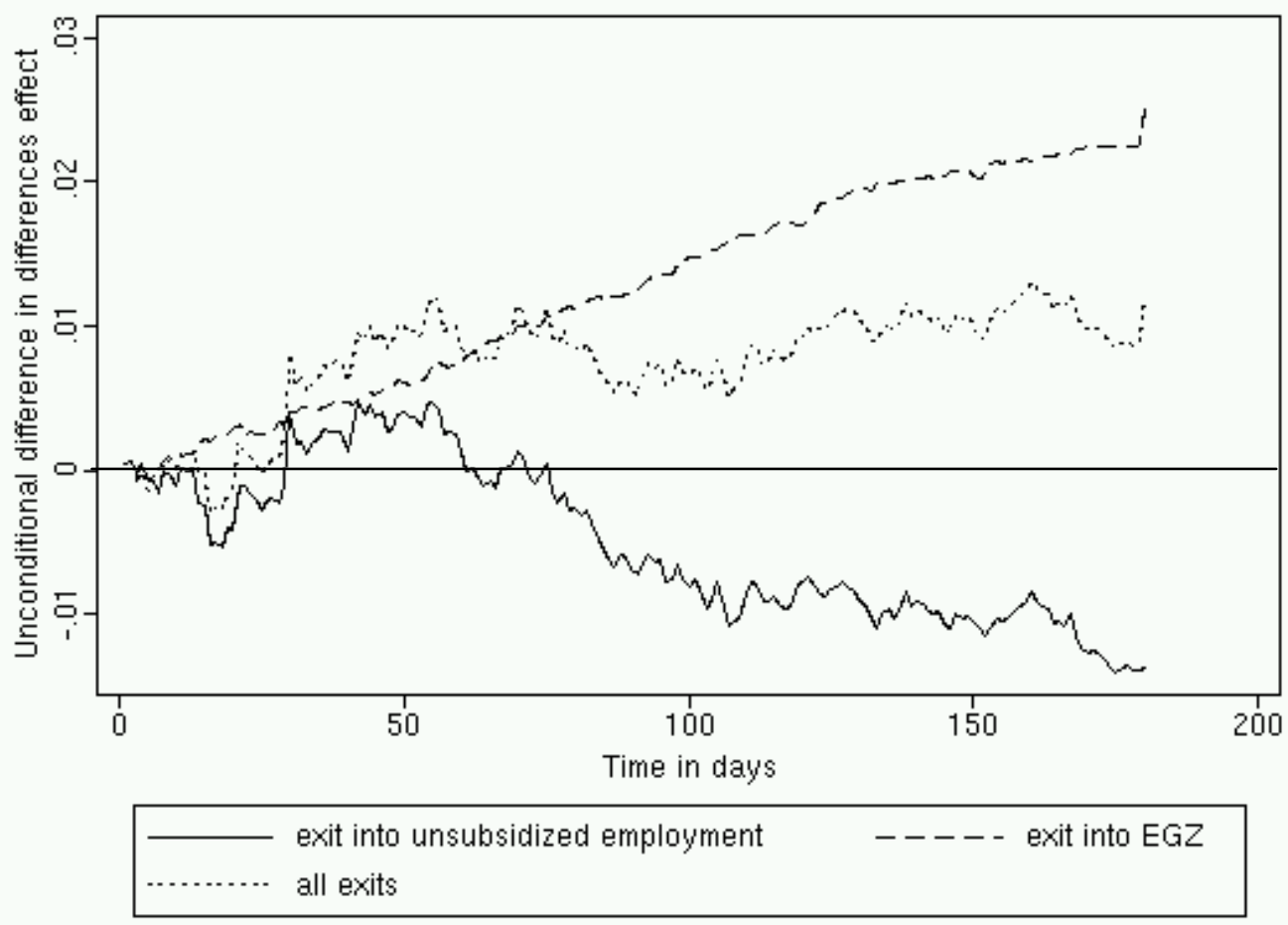

Figure 8: Cumulative incidence function results for the 2004 experiment

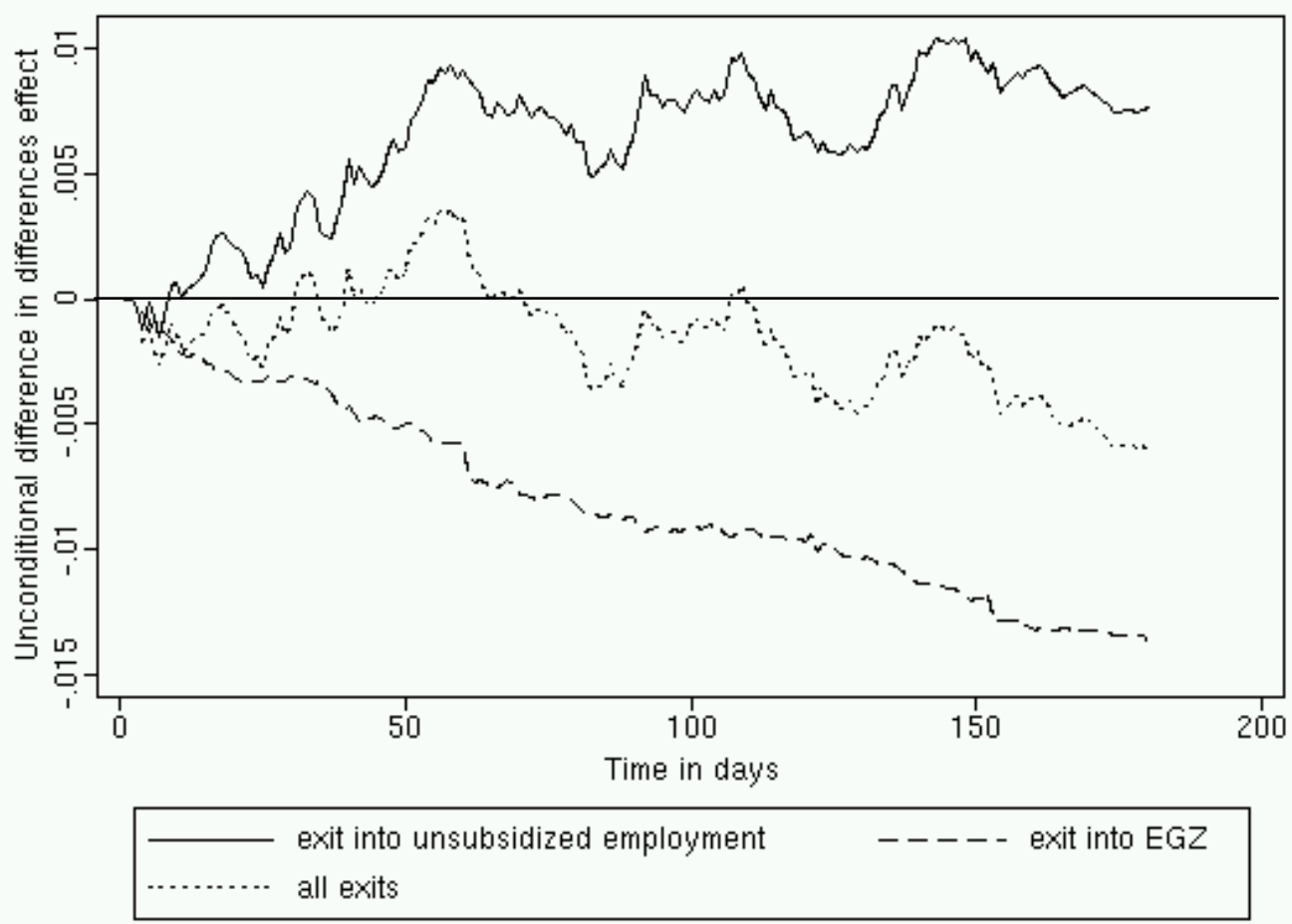


Figure 9: Conditional and unconditional DD Estimates, 2002

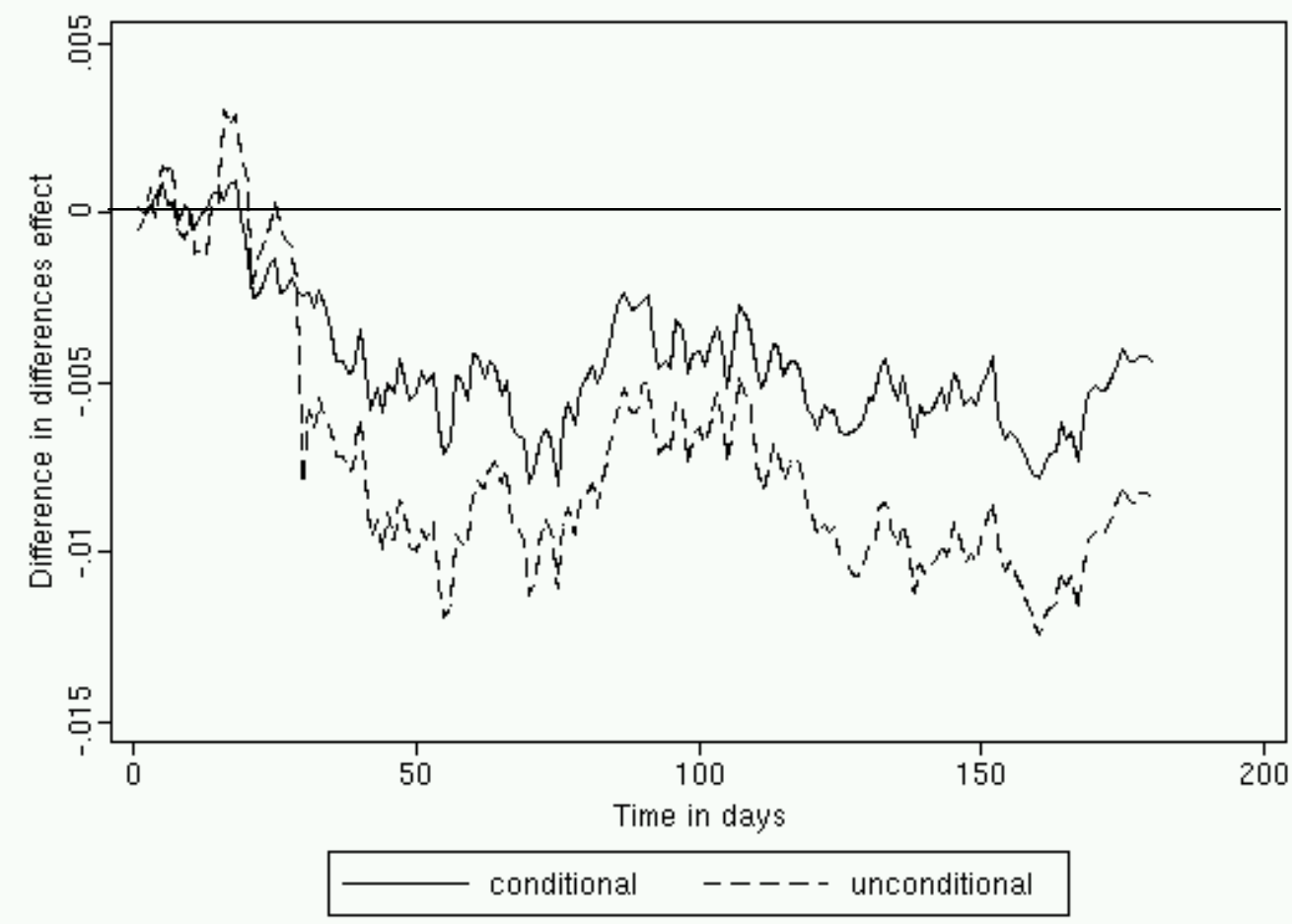

Figure 10: Conditional and unconditional DD Estimates, 2004

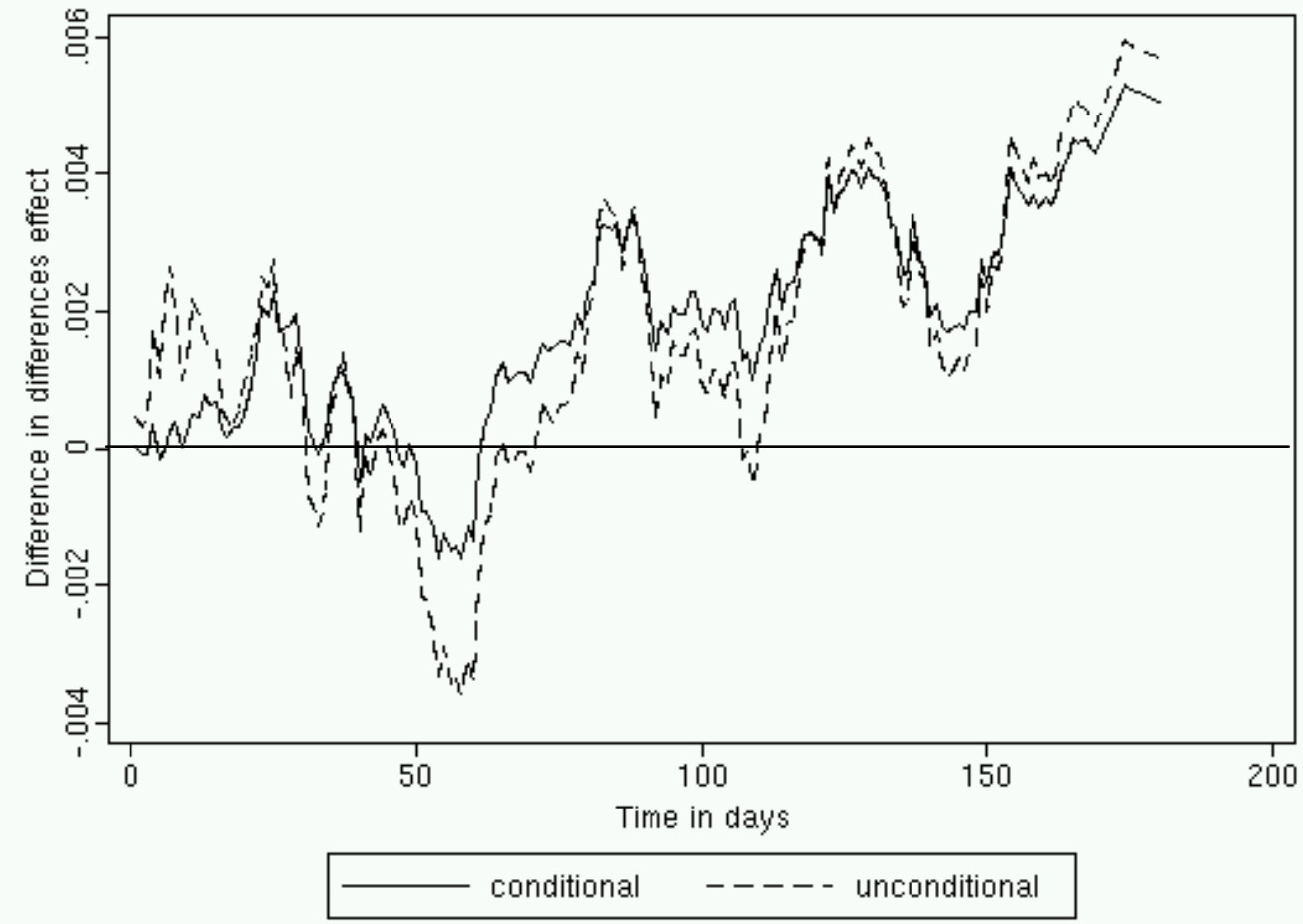


Figure 11: Widening the age groups, 2002

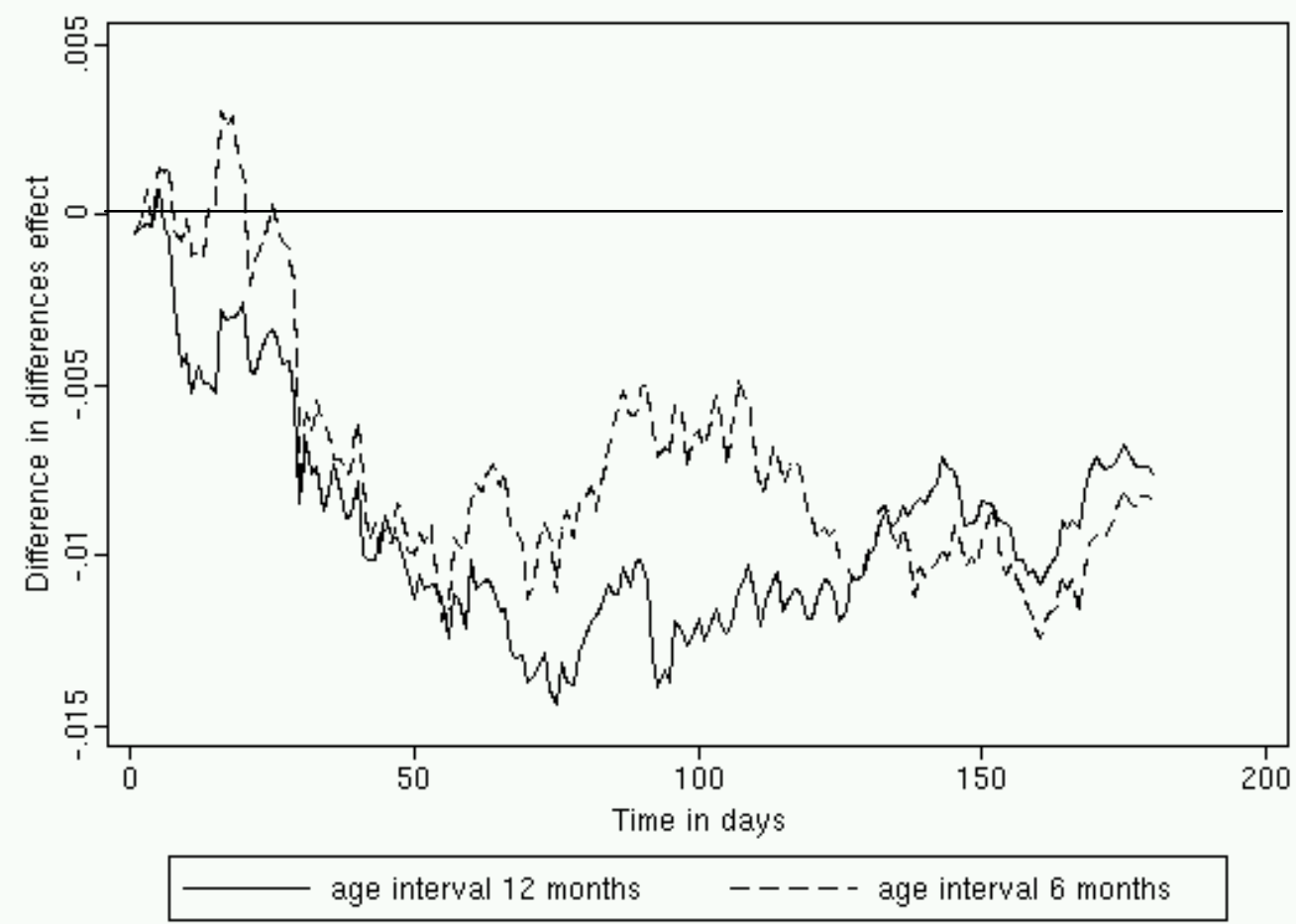

Figure 12: Widening the age groups, 2004

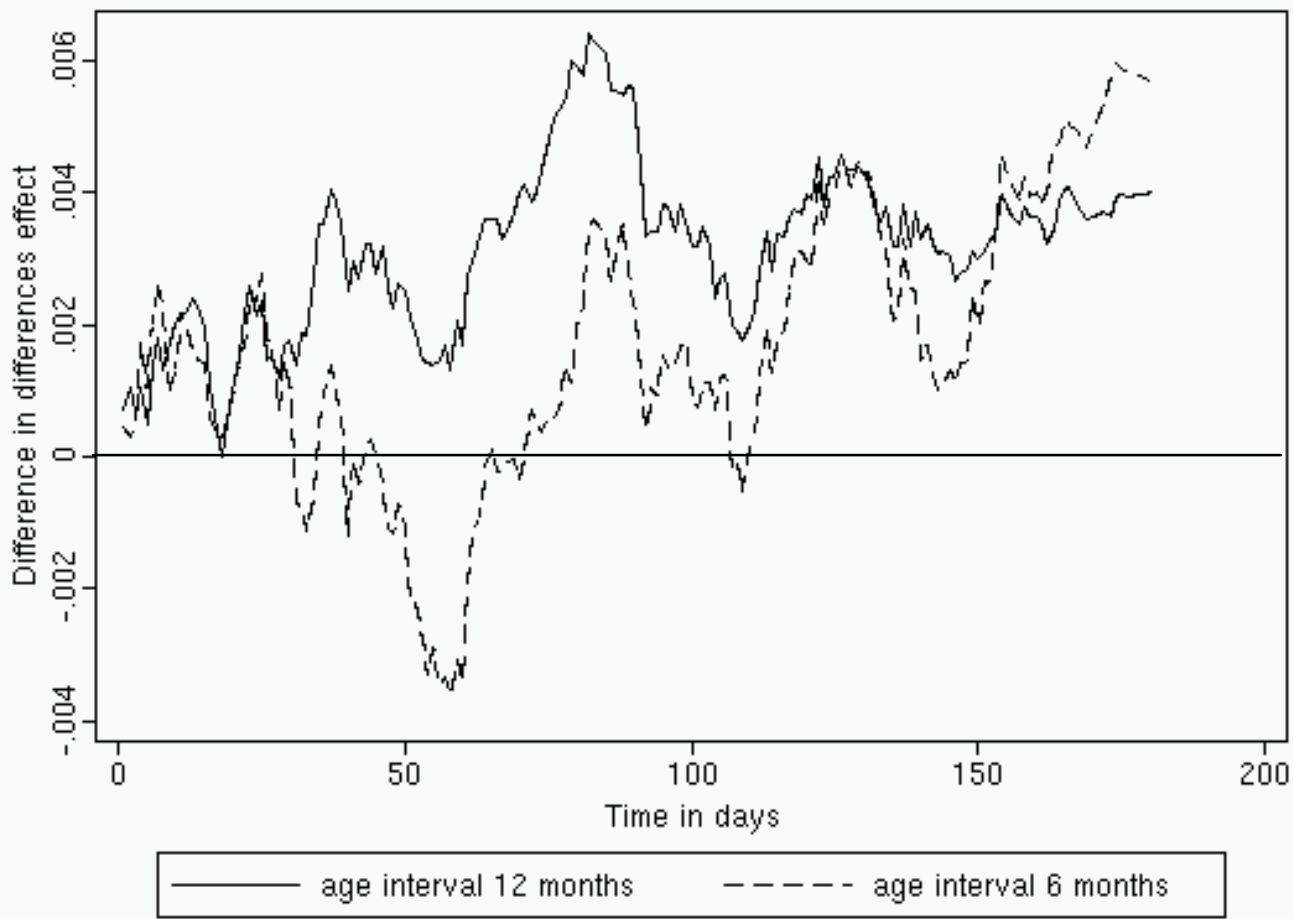


Table 1: Number of EGZ-subsidised hirings as a share of all unemployment spells

\begin{tabular}{lcccc}
\hline \hline & 2001 & 2002 & 2003 & 2004 \\
\hline $\begin{array}{l}\text { Treatment Group } \\
\text { (Age 50 to } \\
\text { 50+6 months) }\end{array}$ & 1.16 & 3.72 & 3.03 & 0.94 \\
$(6209)$ & $(7320)$ & $(14406)$ & $(16389)$ \\
$\begin{array}{l}\text { Control Group } \\
\text { (Age 49 to } \\
\text { 49+6 months) }\end{array}$ & 0.82 & 1.14 & 1.25 & 0.52 \\
& $(6453)$ & $(6947)$ & $(14374)$ & $(17181)$ \\
\hline \hline
\end{tabular}

Note: Number of individuals in parentheses.

Table 2: Estimated survivor function 180 days after entry into unemployment

\begin{tabular}{lcccc}
\hline \hline & 2001 & 2002 & 2003 & 2004 \\
\hline $\begin{array}{l}\text { Treatment Group } \\
\text { (Age 50 to }\end{array}$ & 74.04 & 73.92 & 80.26 & 81.67 \\
$50+6$ months) & $(0.59)$ & $(0.55)$ & $(0.33)$ & $(0.30)$ \\
& & & & \\
$\begin{array}{l}\text { Control Group } \\
\text { (Age 49 to } \\
\text { 49+6 months) }\end{array}$ & 72.21 & 72.93 & 79.95 & 80.79 \\
& $(0.59)$ & $(0.57)$ & $(0.34)$ & $(0.30)$ \\
\hline \hline
\end{tabular}

Note: Standard errors in parentheses. 
Table 3: Means of independent variables

\begin{tabular}{lcccccccc}
\hline \hline Variable & \multicolumn{2}{c}{2001} & \multicolumn{2}{c}{2002} & \multicolumn{2}{c}{2003} & \multicolumn{2}{c}{2004} \\
\hline Groups & Control & Treatment & Control & Treatment & Control & Treatment & Control & Treatment \\
\hline Married / living together & 0.735 & 0.728 & 0.719 & 0.719 & 0.674 & 0.683 & 0.659 & 0.664 \\
Lone parent & 0.025 & 0.023 & 0.032 & 0.028 & 0.039 & 0.034 & 0.047 & 0.042 \\
Job experience & 0.946 & 0.951 & 0.813 & 0.830 & 0.867 & 0.872 & 0.873 & 0.877 \\
Unskilled worker & 0.481 & 0.472 & 0.471 & 0.478 & 0.463 & 0.448 & 0.455 & 0.452 \\
Skilled worker & 0.427 & 0.429 & 0.417 & 0.411 & 0.445 & 0.456 & 0.454 & 0.455 \\
Technical school degree & 0.026 & 0.030 & 0.043 & 0.040 & 0.032 & 0.031 & 0.030 & 0.031 \\
Technical college degree & 0.023 & 0.024 & 0.024 & 0.023 & 0.024 & 0.026 & 0.028 & 0.027 \\
University degree & 0.042 & 0.046 & 0.045 & 0.047 & 0.036 & 0.039 & 0.036 & 0.034 \\
One child living in household & 0.164 & 0.142 & 0.153 & 0.143 & 0.174 & 0.161 & 0.174 & 0.157 \\
Two children living in & 0.071 & 0.054 & 0.065 & 0.059 & 0.076 & 0.069 & 0.088 & 0.070 \\
household & & & & & & & & 0.039 \\
Three or more children living & 0.028 & 0.026 & 0.028 & 0.023 & 0.035 & 0.029 & 0.039 & 0.031 \\
in household & & & & & & & & \\
Female & 0.463 & 0.470 & 0.449 & 0.450 & 0.467 & 0.466 & 0.455 & 0.461 \\
Foreign national & 0.151 & 0.151 & 0.139 & 0.135 & 0.114 & 0.110 & 0.119 & 0.109 \\
\hline \hline
\end{tabular}

Note: All variables defined as dummy variables 


\section{Appendix}

Table A1: Results from Cox estimation

\begin{tabular}{lllll}
\hline \hline Variable & & 2002 & \multicolumn{2}{c}{2004} \\
\hline Married / living together & 1.12 & $(3.34)$ & 1.44 & $(14.44)$ \\
Lone parent & 1.11 & $(1.03)$ & 1.32 & $(4.53)$ \\
Job experience & 1.48 & $(7.56)$ & 1.36 & $(8.81)$ \\
Unskilled worker & 1.20 & $(5.84)$ & 1.38 & $(14.43)$ \\
Technical school degree & 1.01 & $(0.15)$ & 1.29 & $(4.59)$ \\
Technical college degree & 0.73 & $(2.98)$ & 0.99 & $(0.12)$ \\
University degree & 0.80 & $(2.84)$ & 1.07 & $(1.13)$ \\
One child living in household & 0.99 & $(0.28)$ & 0.96 & $(1.59)$ \\
Two children living in household & 1.09 & $(1.61)$ & 0.88 & $(3.10)$ \\
Three or more children living in household & 0.86 & $(1.51)$ & 0.74 & $(4.85)$ \\
Female & 0.70 & $(12.07)$ & 0.71 & $(16.13)$ \\
Foreign national & 0.78 & $(4.65)$ & 0.78 & $(6.11)$ \\
\hline Number of observations & 23515 & & 56772 & \\
LR chi2(12) & 362.10 & 944.94 & \\
Prob > chi2 & 0.00 & & 0.00 & \\
\hline Nas re & & & &
\end{tabular}

Notes: reference categories: single household; skilled worker, no children in the household. Estimation method: Proportional hazard. In parentheses: z-statistics estimated robustly. 